\title{
Real-life Management Strategy of COVID-19 Patients in Bangladesh with No Death: An Observational and Cohort Study
}

\author{
AKM Faizul Huq ${ }^{1}$, Md Fashiur Rahman ${ }^{2}$, Md Azizul Islam $^{3}$, Syed A lqbal ${ }^{4}$, Azizur Rahman ${ }^{5}$, Syed Abul Hassan Md Abdullah $^{6}$, \\ Mamun Al Mahtab7, Sheikh MF Akbar ${ }^{8}$
}

\begin{abstract}
Background: Coronavirus disease 2019 (COVID-19), caused by severe acute respiratory syndrome coronavirus 2 (SARS-CoV-2), has been declared as pandemic by World Health Organization (WHO) with increasing morbidity (more than 4.6 million patients) and mortality (300,000 deaths). The world-wide target of management COVID-19 is to reduce complications with available management options; this become highly variable from country to country and even within different regions of the same country.

Aim and objective: This observational prospective study represents a single center study in which all patients in this cohort received almost similar medicines and care.

Materials and methods: All patients in this cohort ( $N$ : 32$)$ were positive for SARS-CoV-2 by polymerase chain reaction (PCR) with variable presenting symptoms. The management strategy included Standard of Care (SoC) and administration of hydroxychloroquine and doxycycline. Out of 32 patients, 9 patients also received favipiravir. All patients were followed until they were discharged after negativity of SARS-CoV-2 confirmed by PCR on two consecutive occasions taken within 2 days.

Results: No death has been recorded in this cohort of 32 patients within the study period. The average hospital staying duration was 13.9 days with a range of 8-21 days. All patients were discharged with improvement of subjective symptoms and SARS-CoV-2 negativity. The vital signs (pulse, blood pressure) as well as and levels of electrolyte and blood counts were within normal and acceptable ranges at the time of discharge. Conclusion: The study presented here provide and evidence of a real-life situation of management of limited numbers of COVID-19 patients at a tertiary center of Bangladesh. This study inspires optimism that proper diagnosis, establishment of effective inclusion and exclusion criteria, ensuring application of proper SoC with drugs available in Bangladesh may be a practical option for management of COVID-19 in the country. Keywords: Bangladesh, COVID-19, Management, Zero mortality.

Euroasian Journal of Hepato-Gastroenterology (2020): 10.5005/jp-journals-10018-1316
\end{abstract}

\section{INTRODUCTION}

In December 2019, a new infection by coronavirus, named severe acute respiratory syndrome coronavirus 2 (SARS-CoV-2) caused acute respiratory infection in Wuhan, Hubei Province, China, and quickly spread around the world; this was declared as a global concern (pandemic) by the World Health Organization (WHO). ${ }^{1,2}$ The unexpected pandemic set off by the COVID-19 has caused severe panic among people worldwide. COVID-19 has created havoc, and scientists and physicians have been provided with two major responsibilities; the first one is regarding containment of the virus by (a) complete lockdown, (b) partial lockdown, (c) self-lockdown, (d) introduction of physical distancing concept, (e) development of complicated PCR facilities for diagnosis, and (f) quarantine and isolation concepts at vulnerable places. The next major challenge is to develop proper management strategies for COVID-19 patients. COVID-19 is a progressive disease entity and the pathogenesis of the disease vary considerably. ${ }^{3}$ In one end, several patients of COVID-19 remain asymptomatic and the only feature of COVID-19 is the presence of SARS-CoV-2 in the nasal swab or other body fluid or tissues. ${ }^{4}$ A second group of patients develops subjective symptoms like malaise, weakness, fever, loss of appetite, and change of taste with nominal respiratory distress. ${ }^{5,6}$ Finally, some patients develop serious respiratory symptoms such as pneumonia and ultimately develop multiple organ failure. ${ }^{7}$ The molecular and

\author{
1,4,5 Department of Medicine, Combined Military Hospital, Dhaka, \\ Bangladesh \\ ${ }^{2,3}$ Bangladesh Army Medical Corps, Dhaka, Bangladesh \\ ${ }^{6}$ US CDC, Bangladesh Office, Dhaka, Bangladesh \\ ${ }^{7}$ Department of Hepatology, Bangabandhu Sheikh Mujib Medical \\ University, Dhaka, Bangladesh \\ ${ }^{8}$ Department of Gastroenterology and Metabology, Ehime University \\ Graduate School of Medicine, Ehime, Japan; Miyakawa Memorial \\ Research Foundation, Tokyo, Japan
}

Address reprint requests to: AKM Faizul Huq, Department of Medicine, Combined Military Hospital, Dhaka, Bangladesh, Phone: +8801819102621, e-mail: faiz917@gmail.com

How to cite this article: Huq AKMF, Rahman MF, Islam MA, et al. Reallife Management Strategy of COVID-19 Patients in Bangladesh with No Death: An Observational and Cohort Study. Euroasian J HepatoGastroenterol 2020;10(1):31-35.

Source of support: Nil

Conflict of interest: None

cellular mechanisms underlying these diversities are yet to be explored and it is assumed that distorted immunity such as low responsiveness to interferon at the early stage and cytokine storm at the late stage of the disease may play cardinal roles in the 
pathogenesis of COVID-19. ${ }^{8}$ However, all these hypothesis, theory and observations should be confirmed by scientific evidences as COVID-19 may be more complex disease with involvement of multiple organs and tissues. $^{9}$

Bangladesh, a country of 170 million people, detected its first case of COVID-19 on 8th March 2020 and the first fatality was recorded on 18th March 2020. The numbers of COVID-19 patients with morbidity and mortality have been increasing since then. Although it will be too early to provide any specific comments about world-wide epidemiology of SARS-CoV-2, the extent of infection, numbers of COVID-19 patients and degree of severity of COVID-19 in Asian and African countries seem to be different from those in China, Europe and USA, where COVID-19 induced severe panic as the morbidity and mortality were extremely high. These factors indicate that there is a pressing need of optimization of anti-COVID-19 therapy and management in Bangladesh ${ }^{10}$ without total copying the management strategies of COVID-19 of China or Europe or USA. In other words, we need a strategy of containment of SARS-CoV-2 and management of COVID-19 on the basis of several realities of our country, social position, economic strategy and health care delivery system. Our real-life situation also indicates that we need to develop a comparatively cheaper and effective therapy for management of COVID-19 patients. And, this can be optimized by conducting several trials of different natures so that the best and affordable one can be finally selected.

This observational study presented here has been accomplished in a highly disciplined hospital of Bangladesh in which 32 patients with COVID-19 received a simple and comparatively cheaper therapy and management strategy with proper emphasis on health care delivery maneuvers with objective-oriented nursing services. The study may be a model for management of COVID-19 patients in developing and resource-constrained countries of Asia and Africa.

\section{Materials and Methods}

\section{Patients}

The study was conducted at Combined Military Hospital (CMH) at Dhaka, Bangladesh. This is a single center study and observational in nature. The study is of prospective type. The study has been approved by the hospital authority. Informed consent was taken from all patients if and when necessary. The study has been planned as a duration-based management study of one-month duration; it was started on 6th April 2020 and terminated on 5th May 2020. Only, the adults over the age of 16 years have been enrolled in this observational study. This study was conducted based on a protocol designed before the study was initiated. As per protocol, various vital signs, basic hematological data, parameters of liver and kidney functions, levels of oxygen saturation, and different important electrolytes were checked during admission and at different interval. Before being included in this observational study, they were tested for SARS-CoV-2 in nasal swab and all of them were positive for SARSCoV-2. The criteria for discharge was being negative for SARS-CoV-2 in 2 consecutive assessments. A total of 32 patients could be finally analyzed on the basis of inclusion and exclusion criteria.

\section{Therapeutic Regimen}

All patients received standard of Care (SoC) therapy as per recommendation of the attending physician based on their clinical conditions and pathological evaluations. These included antipyretic drugs to control fever, pain killers for alleviating pain, oxygen for controlling respiratory distress and saline for maintaining proper hydration. One drug regimen on the basis of the recommendation of $\mathrm{CMH}$ was applied to all patients. The drugs included hydroxychloroquine and doxycycline. Hydroxychloroquine was given at a dose $(400 \mathrm{mg}$, twice daily on first day, followed by $200 \mathrm{mg}$, thrice daily from day 2 to 10). Doxycycline was given at a dose of $100 \mathrm{mg}$, twice daily for 10 days. In 9 patients, favipiravir at dose of $1600 \mathrm{mg}$, twice daily, was given on day 1 and this was followed by $600 \mathrm{mg}$, twice daily, from 2 nd to 10th days. If the patients recovered from symptoms of COVID-19 and became negative for SARS-CoV-2 before, the patients were discharged early. Follow up of all patients is continuing.

\section{Trial Procedure}

The patients were properly assessed about vital signs, and physical examination was done at admission. Also, all new symptoms and aggravation of pre-existing symptoms were monitored. Peripheral blood was taken from each patient to check complete blood picture, levels of hemoglobulin, creatinine, bilirubin, and alanine aminotransferase (ALT) to develop insights about the condition of vital organs. X-ray of chest and ECG were accomplished as and when necessary. Oxygen saturation was monitored regularly and all preparations were adopted to provide oxygen supply. Also, ventilator facilities were at hand for usage.

\section{Statistical Analysis}

The data have been shown as mean and standard deviation as well as median and range. For the statistical analysis, paired $t$ test was used for normally distributed data. When the distribution was skewed, the Wilcoxon signed-rank test was used. A $p$ value of less than 0.05 was regarded as statistically significant.

\section{Results}

Out of 32 patients with COVID-19, 27 were male and 5 were female. The patients were comparatively younger and the mean age was 37.7 years (range 16-54 years). In this cohort, some patients also had co-morbidities in addition to be positive for SARS-CoV-2, as shown in Table 1. Hypertension was reported in five, whereas diabetes mellitus was seen in four patients. Three patients provided history of intake of medicine.

The presenting symptoms of the patients were variable. Thirteen of 32 patients had fever and 17 patients were suffering from cough. Additionally, headache, sore throat, and breathing difficulty were found in nine, five, and three patients, respectively. Myalgia, loose motion, abdominal pain, loss of taste, and vomiting were present in some patients (Table 2 ).

All patients were examined properly during admission and all requisite investigations were also accomplished. The data of investigational parameters have been given in Table 3.

Different vital signs and parameters of blood for assessing overall conditions of the patients were checked regularly. The body temperature was elevated in some patients, but very high fever was rare. The body temperature fell significantly during discharge compared to admission point (Table 3). Interesting findings were noted regarding the levels of ALT. The mean level of ALT did not show any statistical differences between admission and discharge. However, ALT levels were higher than upper limit of normal value in 11 patients during admission, whereas, ALT was elevated in 13 patients during discharge (individual data not shown). Overall, the levels of oxygen saturation were of normal value during discharge from hospital. The parameter of kidney function, such as blood 
Real-life Management Strategy of COVID-19 Patients in Bangladesh with No Death

Table 1: General information, comorbidities and drug history of patient with COVID-19

\begin{tabular}{|c|c|c|c|c|}
\hline \multicolumn{3}{|l|}{ Variables } & \multirow{2}{*}{$\begin{array}{l}\text { Numbers } \\
32\end{array}$} & \multirow{2}{*}{$\begin{array}{l}\text { Percentage } \\
100\end{array}$} \\
\hline Demographics & Total & & & \\
\hline & Sex & Female & 5 & 16 \\
\hline & & Male & 27 & 84 \\
\hline & Age (years) & Mean \pm SD & $37.7 \pm 9.5$ & \\
\hline & & Median (range) & $35(16-54)$ & \\
\hline \multirow[t]{4}{*}{ Comorbidities } & Diabetes mellitus & & 4 & 13 \\
\hline & Hypertension & & 5 & 16 \\
\hline & Hypothyroidism & & 1 & 3 \\
\hline & Chronic obstructive & ary disease & 1 & 3 \\
\hline \multirow[t]{2}{*}{ Drug history } & $\begin{array}{l}\text { ACE inhibitor, } \beta \text { blo } \\
\text { blocker }\end{array}$ & ium channel & 2 & \\
\hline & Levothyroxine & & 1 & 3 \\
\hline
\end{tabular}

Table 2: Presenting clinical complains of patient with COVID-19 on the day of admission

\begin{tabular}{llc}
\hline Variables & Numbers & Percentage \\
\hline SARS-CoV-2 positive & 32 & 100 \\
Fever & 13 & 41 \\
Cough & 17 & 53 \\
Headache & 9 & 28 \\
Sore throat & 5 & 16 \\
Breathing difficulty & 3 & 9 \\
Myalgia & 6 & 19 \\
Loose motion & 6 & 19 \\
Abdominal pain & 1 & 3 \\
Loss of taste & 3 & 9 \\
Vomiting & 1 & 3 \\
\hline
\end{tabular}

creatinine was not elevated due to therapy. Also, electrolyte imbalance was not seen in any patient (Table 3). The notable one is the significant decrease of serum hemoglobulin level during discharge compared to admission levels (Table 3).

\section{Discussion}

COVID-19 has induced panic among general population as well as within physicians and policy makers mainly due to its high infective potential, and as considerable numbers of patients have been progressing to intractable pneumonia with substantial fatality. As of May, about 4.5 million people have been infected by SARSCoV-2 causing about 300,000 death within a period of 3 months. ${ }^{10}$ Worldwide lockdown, maintaining of social distancing, and several approaches for vaccine development have been adopted for control of expansion of infection. At the same time, utmost attention has been focused to management of COVID-19 patients so that mortality may be contained.

As the pathogenesis of COVID-19 has not been properly addressed till now, several types of therapies have been adopted in different countries of the world and even in different hospitals of the same country. The treatment of COVID-19 should be scientificallybased on two basic fundamentals. The first one is to control viral replication and the next is to block progression of pathogenesis, especially minimizing occurrence of pneumonia. ${ }^{8}$ To achieve these targets, several lines of treatment have been adopted by physicians of different countries. Several antiviral drugs are now used to
Table 3: Clinical and pathological features of patient with COVID-19

\begin{tabular}{|c|c|c|c|}
\hline \multicolumn{2}{|l|}{ Variables } & \multirow{2}{*}{$\begin{array}{l}\text { Day of admission } \\
98.19 \pm 1.89\end{array}$} & \multirow{2}{*}{$\begin{array}{l}\text { Day of discharged } \\
96.90 \pm 1.29^{*}\end{array}$} \\
\hline Body & Mean \pm SD & & \\
\hline $\begin{array}{l}\text { Temperature } \\
\left({ }^{\circ} \mathrm{F}\right)\end{array}$ & Median (range) & $98(96-102)$ & $96(96-98.4)$ \\
\hline \multirow{2}{*}{$\begin{array}{l}\text { Pulse rate } \\
\text { (BPM) }\end{array}$} & Mean \pm SD & $81.17 \pm 9.51$ & $77.94 \pm 7.28$ \\
\hline & Median (range) & $79(62-92)$ & $(00.00-00.00)$ \\
\hline \multirow[t]{2}{*}{$\mathrm{SpO}_{2}(\%)$} & Mean \pm SD & $96.78 \pm 1.91$ & $97.30 \pm 1.30$ \\
\hline & Median (range) & 97 (90-99) & 97.5 (95-99) \\
\hline \multirow{2}{*}{$\begin{array}{l}\text { Hemoglob- } \\
\text { ulin (g/dL) }\end{array}$} & Mean \pm SD & $13.86 \pm 1.23$ & $13.87 \pm 1.22$ \\
\hline & Median (range) & $13.85(11.30-16.70)$ & $14.05(10.8-15.6)$ \\
\hline \multirow[t]{2}{*}{ WBC $\left(\mathrm{mm}^{3}\right)$} & Mean \pm SD & $6,139 \pm 1,578$ & $7,500 \pm 2,368^{*}$ \\
\hline & Median (range) & $5,900(4,000-9,500)$ & $6,450(4,500-14,000)$ \\
\hline \multirow{2}{*}{$\begin{array}{l}\text { Neutrophil } \\
\text { (\%) }\end{array}$} & Mean \pm SD & $58.69 \pm 12.38$ & $56.38 \pm 11.55$ \\
\hline & Median (range) & $56(23-78)$ & $52.5(37-83)$ \\
\hline \multirow{2}{*}{$\begin{array}{l}\text { Platelet } \\
\left(\mathrm{mm}^{3}\right)\end{array}$} & Mean \pm SD & $201 \pm 46.17$ & $275 \pm 84^{*}$ \\
\hline & Median (range) & 195 (90-295) & $255(150-476)$ \\
\hline \multirow{2}{*}{$\begin{array}{l}\text { Bilirubin } \\
\text { (mg/dL) }\end{array}$} & Mean \pm SD & $0.49 \pm 0.02$ & $0.55 \pm 0.27$ \\
\hline & Median (range) & $0.4(0.2-0.8)$ & $0.5(0.3-1.2)$ \\
\hline \multirow[t]{2}{*}{$\operatorname{ALT}(\mathrm{U} / \mathrm{L})$} & Mean \pm SD & $43.19 \pm 32.22$ & $57.00 \pm 39.93$ \\
\hline & Median (range) & $35(18-198)$ & $39(14-169)$ \\
\hline \multirow[t]{2}{*}{ AST (U/L) } & Mean \pm SD & $48.28 \pm 20.12$ & $49.72 \pm 23.88$ \\
\hline & Median (range) & $44.5(20-115)$ & $42(16-113)$ \\
\hline \multirow{2}{*}{$\begin{array}{l}\text { Albumin } \\
\text { (g/dL) }\end{array}$} & Mean \pm SD & $4.35 \pm 0.03$ & $4.11 \pm 0.31^{*}$ \\
\hline & Median (range) & $4.4(3.7-5)$ & $4.2(3.3-4.5)$ \\
\hline \multirow{2}{*}{$\begin{array}{l}\text { Creatinine } \\
(\mathrm{mg} / \mathrm{dL})\end{array}$} & Mean \pm SD & $0.85 \pm 0.12$ & $0.82 \pm 0.12$ \\
\hline & Median (range) & $0.8(0.6-1.2)$ & $0.8(0.6-1.2)$ \\
\hline \multirow{2}{*}{$\begin{array}{l}\text { Sodium } \\
\text { (mEq/L) }\end{array}$} & Mean \pm SD & $137.93 \pm 3.26$ & $137.62 \pm 1.66$ \\
\hline & Median (range) & 139 (130-144) & $137(134-140)$ \\
\hline \multirow{2}{*}{$\begin{array}{l}\text { Potassium } \\
(\mathrm{mEq} / \mathrm{L})\end{array}$} & Mean \pm SD & $4.03 \pm 0.39$ & $4.11 \pm 0.44$ \\
\hline & Median (range) & $4.00(3.4-4.9$ & $4.05(2.5-5.0)$ \\
\hline \multirow{2}{*}{$\begin{array}{l}\text { Chloride } \\
\text { (mEq/L) }\end{array}$} & Mean \pm SD & $96.94 \pm 1.90$ & $96.72 \pm 1.85$ \\
\hline & Median (range) & $97(91-101)$ & $97(91-102)$ \\
\hline
\end{tabular}

$\mathrm{SpO}_{2}$, oxygen saturation;WBC, while blood cell; $\mathrm{S}$. ALT, alanine transaminase; AST, aspartate transaminase; SD, standard deviation

Statistical significance was considered when $p$ value was $<0.05$ and shown as * mark

contain replication of SARS-CoV-2 in COVID-19 patients; however, the outcome is still unsatisfactory. In fact, no drugs have been 
developed for COVID-19 and drugs those have been developed for flu, severe acute respiratory syndrome (SARS), Middle-Eastern acute respiratory syndrome (MERS), and Ebola have been used for treatment of COVID-19 in several countries. ${ }^{11,12}$

The observational study presented here used available drugs for management of COVID-19 patients with proper nursing and intensive follow up of all patients; this was possible as the study was conducted in $\mathrm{CMH}$, a highly organized hospital in Bangladesh. Hydroxychloroquine is an anti-malarial drug but endowed with considerable anti-inflammatory properties and this drug has been used for treating COVID-19 patients in various set up. ${ }^{13-16}$ Also, investigators have indicated that there is rationale, pre-clinical evidence of effectiveness and evidence of safety from longtime clinical use for other indications to justify clinical research on hydroxychloroquine in patients with COVID-19. The US and French regulatory authorities have permitted its usage for COVID19 patients. ${ }^{15,17}$ On the other hand, investigators have shown reservations about use of hydroxychloroquine for COVID-19 patients. ${ }^{6}$ Doxycycline possess anti-bacterial properties and this rationalize their use in COVID-19 patients as they are prone to develop pneumonia.

It is natural that there would be considerable discussion about the pros and cons of the drug therapy of COVID-19 patients, as no standardized therapeutic regimen has been approved so far. However, this observational study provides some important realities in the context of COVID-19 management. The first, this is possibly the first and only study that showed zero fatality of COVID-19 patient in a prospective study organized in Bangladesh, a developing and resource-constrained country. This scenario contrasts with thousands of deaths from COVID-19 in developed countries; almost all European countries and USA. The causes underlying this is elusive. However, it may be considered that the SARS-CoV-2 virus that spread in Europe and USA vs Bangladesh may be different. ${ }^{18,19}$ Data supporting this concept has started to emerge. Also, epidemiological data strongly favors such a hypothesis. Although several thousand COVID-19 patients have died in Europe and USA, the fatality is still low in Asian and African countries. The next, if we look at the pathogenesis of SARS-CoV-2, it is apparent that host immunity seems to be regulator regarding acquisition of infection, progression of disease and multi-organ failure including pneumonia. ${ }^{20,21}$ The host immunity to SARS-CoV-2 may be different among human races, but more information would be required to substantiate these hypotheses. Thus, several points may need to be addressed in future by in vitro and in vivo studies and experiments.

The major limitation of the study is small sample size of only 32 patients. However, this may be accepted as an observational study during pandemic situation in a developing country. The next, there has been no control group in this study. In fact, this is not possible to have an absolute control group in the present circumstances of Bangladesh. This study was initiated at the beginning of April for a duration of one month. However, we strongly believe that a large cohort study with bigger sample size and effective control groups using different drug regimens should be conducted in near future in this country. One of the major scopes of this study is that the patients would be followed for any adverse effect in future as all patients are well communicated with the hospital authority of $\mathrm{CMH}$. Thus, we would be able to get data of mid and long-term follow up of COVID-19 patients at Bangladesh.

Taken all these factors together, the main message of this observational study indicates that if early diagnosis, proper monitoring, and timely intervention of COVID-19 patients can be optimized in Bangladesh, it may be possible to contain the major bulk of COVID-19 patients with comparatively cheaper therapeutic regimen and with minimum fatality. However, reproduction of this endeavor and follow up data of the patients are urgently needed to move forward. The concept of our study may be applied for management of COVID-19 patients in other developing countries of Asia and Africa, those share similar socio-economic parameters with Bangladesh.

\section{References}

1. Munster VJ, Koopmans $\mathrm{M}$, van Doremalen $\mathrm{N}$, et al. A novel coronavirus emerging in China-key questions for impact assessment. N Engl J Med 2020;382(8):692-694. DOI: 10.1056/NEJMp2000929.

2. Wilder-Smith A, Chiew CJ, Lee VJ. Can we contain the COVID-19 outbreak with the same measures as for SARS? Lancet Infect Dis 2020;20(5):e102-e107. DOI: 10.1016/S1473-3099(20)30129-8.

3. Zhou F, Yu T, Du R, et al. Clinical course and risk factors for mortality of adult inpatients with COVID-19 in Wuhan, China: a retrospective cohort study. Lancet 2020;395(10229):1054-1062. DOI: 10.1016/S01406736(20)30566-3.

4. Bai $Y$, Yao L, Wei T, et al. Presumed asymptomatic carrier of transmission of COVID-19. JAMA 2020;323(14):1406-1407. DOI: 10.1001/jama.2020.2565.

5. Wang $Y$, Wang $Y$, Chen $Y$, et al. Unique epidemiological and clinical features of the emerging 2019 novel coronavirus pneumonia (COVID19) implicate special control measures. J Med Virol 2020. DOI: 10.1002/ jmv.25748.

6. Guan $\mathrm{WJ}, \mathrm{Ni} \mathrm{ZY}, \mathrm{Hu} \mathrm{Y}$, et al. Clinical characteristics of coronavirus disease 2019 in China. N Engl J Med. 2020 382(18):1708-1720. DOI: 10.1056/NEJMoa2002032.

7. Du RH, Liang LR, Yang CQ, et al. Predictors of mortality for patients with COVID-19 pneumonia caused by SARS-CoV-2: a prospective cohort study. Eur Respir J 2020;55(5):2000524. DOI: 10.1183/13993003.005242020.

8. Tay MZ, Poh CM, Rénia L, et al. The trinity of COVID-19: immunity, inflammation and intervention. Nat Rev Immunol 2020. 1-12. DOI: 10.1038/s41577-020-0311-8.

9. Zaim S, Chong JH, Sankaranarayanan V, et al. COVID-19 and MultiOrgan Response. Curr Probl Cardiol 2020. 100618. DOI: 10.1016/j. cpcardiol.2020.100618.

10. World Health Organization. Coronavirus disease (COVID-19) Pandemic. https://www.who.int/emergencies/diseases/novelcoronavirus-2019, May 11th 2020.

11. Triple combination therapy shows promise for COVID-19 patients with less severe illnesses. https://abcnews.go.com/Health/ triple-combination-therapy-shows-promise-covid-19-patients/ story? id $=70580878$.

12. Hung IF, Lung KC, Eugene YK, et al. Triple combination of interferon beta-1b, lopinavir-ritonavir, and ribavirin in the treatment of patients admitted to hospital with COVID-19: an open-label, randomised, phase 2 trial. Lancet 2020. DOI: 10.1016/S0140-6736(20)31042-4.

13. Jin $\mathrm{YH}, \mathrm{Cai} \mathrm{L}, \mathrm{Cheng} \mathrm{ZS}$, et al. A rapid advice guideline for the diagnosis and treatment of 2019 novel coronavirus (2019-nCoV) infected pneumonia (standard version). Mil Med Res 2020;7(1):4. DOI: 10.1186/ s40779-020-0233-6.

14. Geleris J, Sun Y, Platt J, et al. Observational study of hydroxychloroquine in hospitalized patients with COVID-19. N Engl J Med 2020. DOI: 10.1056/NEJMoa2012410.

15. Cortegiani A, Ingoglia G, Ippolito M, Giarratano A, Einav S. A systematic review on the efficacy and safety of chloroquine for the treatment of COVID-19. J Crit Care 2020;57:279-283. DOI: 10.1016/j.jcrc.2020.03.005.

16. Yao X, Ye F, Zhang M. In vitro antiviral activity and projection of optimized dosing design of hydroxychloroquine for the treatment of severe acute respiratory syndrome coronavirus 2 (SARS-CoV-2). Clin Infect Dis 2020. DOI: 10.1093/cid/ciaa237. 
17. Jaffe S. Regulators split on antimalarials for COVID-19. Lancet 2020;395(10231):1179. DOI: 10.1016/S0140-6736(20) 30817-5.

18. Owens B. Excitement around hydroxychloroquine for treating COVID-19 causes challenges for rheumatology. Lancet Rheumatol 2020;2(5):e257. DOI: 10.1016/S2665-9913(20)30089-8.

19. He HJ, Zhang W, Liang J, et al. Etiology and genetic evolution of canine coronavirus circulating in five provinces of China, during 2018-
2019. Microb Pathog 2020;145:104209. DOI: 10.1016/j.micpath.2020. 104209.

20. van Dorp L, Acman M, Richard D, et al. Emergence of genomic diversity and recurrent mutations in SARS-CoV-2. Infect Genet Evol 2020;83:104351. DOI: 10.1016/j.meegid.2020.104351.

21. Ye Q, Wang B, Mao J. The pathogenesis and treatment of the 'Cytokine Storm' in COVID-19. J Infect 2020;80(6):607-613. DOI: 10.1016/ j.jinf.2020.03.037. 